\title{
REPRESENTATIONS, JUDGMENTS, AND THE SWAMPING PROBLEM FOR RELIABILISM: WHY THE PROBLEM APPLIES TO PROCESS RELIABILISM, BUT NOT TO VIRTUE RELIABILISM
}

\author{
Ernest Sosa ${ }^{1}$
}

\begin{abstract}
This article argues for a way out of the swamping problem by showing where his virtue epistemology substantially departs from traditional process reliabilism and how such departure is enough to protect the former from issues that affect the way the latter accounts for the value of knowledge over mere true belief.
\end{abstract}

Keywords: Virtue Epistemology. Process Reliabilism. Swamping Problem. Value of Knowledge.

\section{REPRESENTATIONS}

1. Representations have central importance for virtue epistemology. Affirmations are a species of representations, explicit representations, with several varieties.

Affirming that one is the queen is saying that one is the queen, which requires more than just saying 'I am the queen' as this could be by an actress on the stage. Alethic affirmation requires a saying that $\mathrm{p}$ in the endeavor to say what is true.

Judgment requires aiming not only at truth but also at aptness (as in the diagnosis of an oncologist, unlike the guess of a quiz show contestant).

2. Functional alethic representations are implicit representations teleologically aimed at truth, at representing correctly, and also at corresponding ${ }_{1}^{1}$ Departament of Philosophy at Rutgers University, New Jersey - USA. (D) https://orcid.org/0000-
0002-2465-8988 E-mail: sosaern@gmail.com

https://doi.org/10.1590/0101-3173.2021.v44dossier2.03.p19

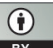


aptness, where the correctness is not guess-like, but judgment-like, since it is aimed at representing not only correctly but competently and indeed aptly, at correctness that will not be just by luck, but will manifest competence. ${ }^{2}$

3. Representations come in various forms: explicit, implicit, verbal, public, private, conceptual, nonconceptual. They are all episodic, not just dispositional, have truth-evaluable content (truth-evaluable at least contextually), and might constitute reasoning that can explain conduct.

\section{Conscious Judgments}

1. In what follows the conscious judgment is front and center, as implicit representations will remain in the background. What is the judgment itself? We could conceive of it as the affirmation, but in telic virtue epistemology, we focus on the whole attempt, and not just on the affirmation nor even just on the alethic affirmation. We focus on the attempt to get it right aptly, and not just on the alethic affirmation whereby the thinker attempts to attain truth.

Our "alethic affirmation that p" is the attempt to get it right on whether p by affirming that $\mathrm{p}$. So, the alethic affirmation is not just the affirmation with the property of being aimed at truth. It is rather the attempt itself to get it right by affirming that $\mathrm{p}$.

2. In our telic framework, judgments are thus attempts that attain to fully apt reflective knowledge if all goes well. Success, adroitness, aptness, and full aptness are then properties both of alethic affirmations (of attempts to get it right by affirming), and of judgments (of attempts to get it right aptly by alethically affirming).

\section{THE SWAMPING PROBLEM FOR RELIABILISM}

1. According to generic process reliabilism, a belief is justified to the extent that the relevant process from which it derives is one that reliably enough yields beliefs that are true rather than untrue. A belief is here viewed

2 Compare the instinctive sphex with the plover who ostensibly opts deliberatively, or quasideliberatively, from a much broader fan of options. Only the latter begins to approach truth-directed representations that might explain behavior when combined with antecedent goals in a kind of practical reasoning. 
as a product quite distinct from the process that produces that product. Thus, for example, a belief can be viewed as a sort of map, one separable from the "cartographic" process that yields it.

A problem for such reliabilism is raised originally by Linda Zagzebski (1996) through her analogy with a good espresso produced by use of an espresso machine. The quality of that cup of coffee is determined by how tasty it is, which is independent from the reliability of the process that produces it. A terrible espresso machine that normally produces undrinkable coffee may on occasion produce a delicious espresso, whose evaluation is hence unaffected by the reliability score of that process.

Similarly, goes the objection, the relevant epistemic quality of a belief as true is unaffected by the truth-reliability score of the epistemic process that yields that belief. The coffee-pertinent quality of a cup of coffee does not depend on the reliability of whatever process produces it. By analogy, then, the knowledge-pertinent quality of a belief does not depend on the reliability of whatever process produces that belief. Reliabilism is thus said to fail as an account of the knowledge-pertinent epistemic quality of beliefs.

Suppose we do think of beliefs as maps that help us steer. If we wish to go to Larissa, an accurate map will serve us well. In addition, the accuracy of a map could reach its highest level independently of the quality of the cartographic process that produces it. A map could reach the highest accuracy accidentally if the cartographer is just guessing. So, reliability seems as inessential to the accuracy of a map as it is to the quality of a cup of espresso. We can get to Larissa just as well by means of an accurate map that is unreliably produced as by an accurate map that is reliably produced. All that matters to the quality of a map as a guide to action is its degree of accuracy. What mainly matters is that it be accurate enough to guide us well enough to our destination.

Plato's Meno problem can be put thus in terms of beliefs as maps, but the problem clearly extends to beliefs as representations more generally.

Therefore, the problem extends to affirmations generally, whether these take the form of vocalizations or that of inscriptions, or that of subconscious representations. Considered simply as maps to guide action, our affirmations are assessable without regard to our reliability as cartographers. If accurate enough, a map is a good-enough map, regardless of how reliably it came to be that way, in line with Plato's point in the Meno. 
Accuracy is the pertinent epistemic quality of maps, and the same would then seem to be true of beliefs considered simply as guides to steer by. The problem remains if we take the map to be a complex set of dispositions to guide behavior given a set of desires. If we think of that set of dispositions as just lodged in the agent however, it may have got there, we will have another version of the same problem.

So, we have an ostensible problem for any account of a belief's justification in terms of how truth-reliable is the process that produces that belief. This is still a problem if we think of the justification of that belief in terms of how reliably it is put in place so as to guide action well. In addition, it remains a problem even if we think of the pertinent desideratum for that belief as its degree of accuracy, never mind its navigational value. We can focus on that quality of a map, even when it is a map that locates Timbuktu, and we have no plans to go there, nor will or would we ever go there, nor to any other place located on that map. It can still count as a fine map because of its degree of accuracy. But this too is compatible with its having been produced by a terrible cartographic process. So, the analogy with the good espresso remains, and Zagzebski's objection is sustained.

2. In contrast to process reliabilism, telic virtue epistemology takes a different view of judgment and representation and of belief more generally, whether judgmental or functional, conscious or subconscious. Our virtue epistemology takes representations, judgments, and beliefs to be not maps but attempts. ${ }^{3}$ So, the right analogy is not to a product separable from the agent. In our view, the right analogy is rather to the producing, to the agent's attempt to get it right on a given question. Because of that, the reliabilism of telic virtue epistemology is not the reliabilism of process reliabilism. The telic focus is rather on agency, not on process. This enables us to reject the damaging

3 The postulation of subconscious mental acts just comes along with the postulation of implicit reasoning in the explanation of much human and other animal conduct. Suppose we postulate such reasoning in explaining why someone reaches for a glass of water even when they engage consciously in no such reasoning, when instead they just "automatically" reach for the glass that is obviously in their field of vision. Such explanation would seem to require the agent's occurrent acceptance of premises that they do not accept consciously, and this acceptance would seem to count as an act, even if it remains subconscious. Out of the plethora of declarative "sentences" or representations stored in their "belief box," that particular one is then "activated" in an act-like way, so as to function as a premise of their (subconscious) reasoning on that occasion. And the like would seem to be required for folk explanation in animal ethology. (But this is just to hint briefly at a way of thinking about subconscious mental acts and their place in our rational economy.) 
analogies to maps and cups of coffee and their respective sorts of quality. The quality that matters to us is the quality of agency, and thereby the quality of a very distinctive sort of products of agency.

Our focus is on actions, whether those of praxis or those of episteme. This imports a normativity that is telic, and undetachable from the agent and their agency. For virtue epistemology, the epistemic normativity of belief is not detachable from its adroitness, from the degree of reliability of the competence that it manifests. Such normativity of belief is hence not detachable from reliability in contrast to how the quality of a cup of coffee is detachable from the coffee machine and its operation. Our focus is the aimed øing of the agent who øs, the competence that is exercised in that øing, the success of the øing, the aptness of that success, etc.

So, the relevant analogues of the judgments and beliefs of our telic epistemology are not cups of coffee, nor maps. The relevant analogues would be performances of the barista or the cartographer, or even performances of the map-user who plans an itinerary. The focus is not just on the map but on the cartographer's epistemic performance, and on the epistemic use of the map, whether consciously intentional and deliberative, or subconscious and functional.

Our swamping problem turns out accordingly to be a problem not for reliabilism but for process reliabilism. The telic normativity of virtue reliabilism invokes not just processes but exercises of agency, with a focus on epistemic competence and its manifestations, which makes our swamping objection inapplicable to virtue epistemology.

\section{REFERENCE}

ZAGZEBSKI, Linda, Virtues of the Mind: An Inquiry into the Nature of Virtue and the Ethical Foundations of Knowledge. Cambridge: Cambridge University Press, 1996.

Received: 21/8/2020

Approved: 05/3/2021 
SOSA, E. 